\title{
Polylactic acid (PLA)/Silver-NP/VitaminE bionanocomposite electrospun nanofibers with antibacterial and antioxidant activity
}

\author{
Bogdanel Silvestru Munteanu - Zeynep Aytac • \\ Gina M. Pricope · Tamer Uyar • Cornelia Vasile
}

Received: 3 July 2014/ Accepted: 4 September 2014/Published online: 23 September 2014

(C) Springer Science+Business Media Dordrecht 2014

\begin{abstract}
The antibacterial property of silver nanoparticles (Ag-NPs) and the antioxidant activity of Vitamin E have been combined by incorporation of these two active components within polylactic acid (PLA) nanofibers via electrospinning (PLA/Ag-NP/VitaminE nanofibers). The morphological and structural characterizations of PLA/Ag-NP/VitaminE nanofibers were performed by Scanning Electron Microscopy (SEM), Transmission Electron Microscopy and X-ray diffraction. The average fiber diameter was $140 \pm 60 \mathrm{~nm}$, and the size of the Ag$\mathrm{NP}$ was $2.7 \pm 1.5 \mathrm{~nm}$. PLA/Ag-NP/VitaminE
\end{abstract}

Bogdanel Silvestru Munteanu and Zeynep Aytac contributed equally to this work.

B. S. Munteanu

Faculty of Physics, “Al. I. Cuza” University Iasi, 11 Carol

I bvd, Iasi, Romania

Z. Aytac $\cdot$ T. Uyar $(\bowtie)$

UNAM - Institute of Materials Science and

Nanotechnology, Bilkent University, Ankara 06800,

Turkey

e-mail: tamer@unam.bilkent.edu.tr

G. M. Pricope

Veterinary and the Food Safety Laboratory, Food Safety

Department, Iasi, Romania

C. Vasile $(\square)$

Romanian Academy, "P.Poni" Institute of

Macromolecular Chemistry, 41A Grigore Ghica Voda

Alley, 700487 Iasi, Romania

e-mail: cvasile@icmpp.ro nanofibers inhibited growth of Escherichia coli, Listeria monocytogenes and Salmonella typhymurium up to $100 \%$. The amount of released $\mathrm{Ag}$ ions from the nanofibers immersed in aqueous solution was determined by Inductively Coupled Plasma Mass Spectrometry, and it has been observed that the release of $\mathrm{Ag}$ ions was kept approximately constant after 10 days of immersion. The antioxidant activity of PLA/Ag-NP/VitaminE nanofibers was evaluated according to DPPH (2,2-diphenyl-1picrylhydrazyl) method and determined as $94 \%$. The results of the tests on fresh apple and apple juice indicated that the PLA/Ag/VitaminE nanofiber membrane actively reduced the polyphenol oxidase activity. The multifunctional electrospun PLA nanofibers incorporating Ag-NP and Vitamin E may be quite applicable in food packaging due to the extremely large surface area of nanofibers along with antibacterial and antioxidant activities. These materials could find application in food industry as a potential preservative packaging for fruits and juices.

Keywords Electrospinning $\cdot$ Nanofiber $\cdot$ Polylactic acid (PLA) · Silver nanoparticles · Vitamin E · Antibacterial $\cdot$ Antioxidant

\section{Introduction}

Electrospinning is a cost-effective method, applicable for a wide range of polymers in solution or in melt state (Wendorff et al. 2012; Ramakrishna 2005; Doshi 
and Reneker 2007), by which nanofibers/nanowebs with very high surface/volume ratio and nanoporous structures can be obtained, which allow the entrapment of bioactive molecules. The electrospun nanofibers are used in various application areas including filtration, wound dressing, tissue scaffold, drug delivery, energy, catalysis, sensors, environmental, agriculture, and etc. (Wendorff et al. 2012; Ramakrishna 2005) and also proved to have potential applications in food and food packaging as building/reinforcement element of environmentally friendly composites for food packaging material and as building elements of the food matrix for imitation/artificial foods. The electrospinning of nanofibers from biopolymers, biocompatible polymers, or edible polymers is often chosen for food and food packaging applications (Kayaci and Uyar 2012; Kayaci et al. 2013a, 2013b; Fernandez et al. 2009).

In addition, electrospun nanofibers incorporating active agents with antibacterial and/or antioxidant properties which are required for food packaging have been investigated (Kayaci and Uyar 2012; Kayaci et al. 2013a, 2013b; Fernandez et al. 2009). For food safety, such functionality will prevent the invasion of bacteria and micro-organisms and will have a significant impact on shelf-life extension and food safety of products. For instance, high temperature stability and slow release of volatile food additives such as vanillin (Kayaci and Uyar 2012) and eugenol (Kayaci et al. 2013a) by cyclodextrin inclusion complexation encapsulated in electrospun polyvinyl alcohol (PVA) nanofibers were achieved. Glucose oxidase activated the lactoperoxidase (a naturally occurring antimicrobial system in milk) when immobilized in PLA nanofibers (Zhou and Lim 2009).

As regards to biomedical field, materials with antibacterial and antioxidant properties have applications in wound healing (Lee et al. 2007), tissue engineering, as implant coating films, catheters, urethral and ureteral stents, urological implants, and other medical devices. Antibacterial activity against Staphylococcus aureus (S.aureus) and Escherichia coli (E.coli) of polyurethane composite nanofibers containing ciprofloxacin, a fluoroquinolone antibiotic was studied (Choi et al. 2013). The incorporation of curcumin into ultra-fine cellulose acetate nanofibers imparted the antioxidant activity to the resulting fiber mats (Suwantong et al. 2010). Curcumin-loaded polycaprolactone nanofiber matrix is bioactive and has potential as a wound dressing with antioxidant and anti-inflammatory properties (Merrell et al. 2009).

PLA is compatible with many foods, such as dairy products, beverage, fresh meat products, and ready meals. Electrospun PLA nanofibrous webs incorporating triclosan/cyclodextrin inclusion complexes have shown efficient antibacterial activity against Gram positive and Gram negative bacteria (Kayaci et al. 2013b). With regards to biomedical applications, nanofibrous mats from poly(L-lactide) (PLLA) and gelatin/PLLA solutions showed controlled evaporative water loss, promoted fluid drainage ability, and excellent biocompatibility with application as wound dressing (Gu et al. 2009).

Silver nanoparticles (Ag-NPs) can be used as a broad-spectrum antibacterial agent for both Gram positive and Gram negative bacteria in biomedical and food packaging applications. Because of their high reactivity originating from the large surface to volume ratio, Ag-NP can effectively eliminate bacteria and yeasts even at rather low concentrations (Gangadharan et al. 2010). A very low concentration of silver (as low as $1.69 \mu \mathrm{g} / \mathrm{mL} \mathrm{Ag}$ ) gave antibacterial performance in the study of Panácek and others (Panácek et al. 2006). Furthermore, antibacterial activity of $\mathrm{Ag}-\mathrm{NP}$ was found to be dependent on the size of silver particles, since the only nanoparticles that present a direct interaction with the bacteria preferentially have a diameter of approximately 1-10 nm (Morones et al. 2005). The smaller particle size provides improved antibacterial activity (Espinosa-Cristóbal et al. 2009).

Antibacterial property of electrospun nanofibers containing Ag-NP was reported by numerous studies such as PLA/Ag-NP fibers against S.aureus and E.coli (Xu et al. 2006), poly(-ethylene oxide)/Ag-NP fibers intermixed with polyurethane fibers against E.coli (Tijing et al. 2012), polyacrylonitrile/Ag-NP fibers against Gram positive Bacillus cereus and Gram negative Escherichia coli micro-organisms (Shi et al. 2011), and nylon-6/AG-NP nanofibers against both Gram negative Escherichia coli and Gram positive S.aureus (Pant et al. 2012).

In this paper, antioxidant activity of Vitamin E-a fat soluble antioxidant (Traber and Atkinson 2007) was combined with antibacterial property of $\mathrm{Ag}-\mathrm{NP}$ in electrospun PLA nanofibers in order to obtain multifunctional biomaterials. Antibacterial activity of nanofibers was determined by well-known standard methods whereas the antioxidant activity of nanofibers 
was measured using 2,2-diphenyl-1-picrylhydrazyl (DPPH) method. In addition to antibacterial and antioxidant tests, nanofibers were characterized by scanning electron microscopy (SEM), transmission electron microscopy (TEM), X-ray diffraction (XRD), and inductively coupled plasma mass spectrometry (ICP-MS) as well.

\section{Experimental}

\section{Materials}

Polylactic acid (PLA, 2002D, Nature Works) was purchased from Nature Works, USA, with a number average molecular weight of $106 \mathrm{kDa}$ and polydispersity index of 1.64 (determined by GPC). Vitamin $\mathrm{E}$ ( $\alpha$-tocopherol), $\mathrm{AgNO}_{3}$ as silver salt, dichloromethane (DCM, extra pure), N,N-dimethylformamide (DMF, $99 \%$ ), methanol (extra pure), and 2,2diphenyl-1-picrylhydrazyl (DPPH) were obtained from Sigma-Aldrich. The water used in experiments was distilled from a Millipore milli-Q ultrapure water system.

\section{Preparation of silver nanoparticles (Ag-NPs)}

$\mathrm{AgNO}_{3}$ was mixed for $5 \mathrm{~min}$ in DMF and subsequently poured into the previously prepared $10 \%(\mathrm{w} / \mathrm{v})$ PLA solution in DCM. DMF and DCM were in the volumetric ratio of $3 / 7(\mathrm{v} / \mathrm{v})$. The concentration of $\mathrm{AgNO}_{3}$ was adjusted to have $1 \%$ (w/w, with respect to polymer) Ag-NP in the resulting PLA/Ag-NP/ VitaminE nanofibers. After $48 \mathrm{~h}$ stirring in dark $5 \%$ (w/w, with respect to polymer), Vitamin $\mathrm{E}$ in liquid form was added. After $80 \mathrm{~min}$ of the addition of Vitamin E, the solution became dark brown but not turbid. In this process, the reduction of silver salts by DMF can be monitored from the color change of the solution.

\section{Electrospinning of nanofibers}

The experimental set-up for electrospinning device consists of a direct current high voltage power supply (Spellman SL series), a metal plate collector, a syringe pump (Model: KDS 101, KD Scientific), and a syringe oriented with the needle perpendicular to the metal plate. The high voltage is applied between the metal plate and the syringe needle. The polymer solution was loaded into the syringe. The solution is extruded from the needle tip by the syringe pump at a constant flow rate. At the point of ejection (the needle tip) a polymer jet is formed as a result of the electric charge repulsion outgoing the solution surface tension. Electrospinning parameters for obtaining bead-free and uniform PLA nanofibers and PLA/Ag-NP/VitaminE nanofibers were adjusted as: flow rate $16.7 \mu \mathrm{L} / \mathrm{min}$, needle tip-collector distance $10 \mathrm{~cm}$, voltage $15 \mathrm{kV}$, and needle diameter $0.6 \mathrm{~mm}$. Electrospinning was performed at $23{ }^{\circ} \mathrm{C}$ and at $18 \%$ relative humidity in an enclosed Plexiglas box.

Electrospinning was also effectuated using various concentration of Vitamin E (from 0-5.5\%) and AgNP from 0.1-1.5\%). According to other experiments of ours, the increased Vitamin E concentration leads to significant decrease of viscosity, and also the capacity to obtain nanofibres is reduced (Dumitriu et al. 2014), while the increase of the Ag-NP concentration above 0.5-1\% affects the biocompatibility and cell proliferation (Vasile et al. 2013). After several trials, optima concentrations of $5 \%$ Vitamin $\mathrm{E}$ and $1 \% \mathrm{Ag}-\mathrm{NP}$ were chosen.

\section{Measurements and characterization}

Rheometer (Physica MCR 301, Anton Paar) equipped with a cone/plate accessory (spindle type CP 40-2) was used at a constant shear rate of $1001 / \mathrm{sec}$, at $22{ }^{\circ} \mathrm{C}$ to measure the viscosity of the solutions. The conductivity of the solutions was measured with Multiparameter meter InoLab ${ }^{\circledR}$ Multi 720 (WTW) at RT.

Scanning electron microscopy (SEM) images were recorded using a FEI-Quanta 200 FEG microscope. Prior to SEM imaging, nanofibers mounted on metal stubs with double-sided adhesive tape were coated with $5 \mathrm{~nm} \mathrm{Au/Pd}$ (PECS-682) to minimize charging. The fiber diameter of nanofibers was measured directly from the SEM images $(n \geq 100)$ and average fiber diameter (AFD) was calculated.

Transmission electron microscopy (TEM) images were taken using a FEI-Tecnai G2F30 microscope. HC200 grids were attached on the aluminum foil, and the nanofibers were directly electrospun onto the grids. TEM images were acquired in bright field, while scanning transmission electron microscopy (STEM) images were recorded in dark field. 
$\mathrm{X}$-ray diffraction (XRD) analysis of the nanofibers was performed by XRD (PANalytical X'Pert powder diffractometer) using $\mathrm{Cu} K \alpha(\lambda K \alpha=1.54 \AA)$ radiation in a $2 \theta$ range $10-70^{\circ}$.

Inductively coupled plasma mass spectrometry (ICP-MS) measurements were performed using a quadrupole Thermo Scientific XSERIES 2 ICP-MS ICP-MS instrument. $20 \mathrm{mg}$ PLA/Ag-NP/VitaminE nanofibers immersed in $30 \mathrm{~mL}$ deionised water. At certain time intervals (for 20 days), $100 \mu \mathrm{L}$ samples were extracted from PLA/Ag-NP/VitaminE nanofibers immersed aqueous solution, and equal amount of the water was refilled. $50 \mu \mathrm{L}$ of this sample was diluted with $10 \mathrm{~mL}$ solution of $2 \%$ nitric acid/water. Calibration curve was drawn in a concentrations range: $0.3,0.6,1.25,2.5$, and $5.0 \mathrm{ppb}$.

Antibacterial activity

Antimicrobial tests were effectuated according to standard methods SR ISO 16649-2/2007-Microbiology of alimentary and animal products. The experimental protocol for testing antimicrobial efficiency against Escherichia coli, Salmonella typhymurium, and Listeria monocytogenes consists in the following stages: sterilization of samples; ATCC culture bacteria contamination; inoculation and incubation performed for 24 and $48 \mathrm{~h}$ at $44{ }^{\circ} \mathrm{C}$; and identifying target germs.

Sterilization of the samples was made in autoclave at $110{ }^{\circ} \mathrm{C}, 0.5$ bars for $20 \mathrm{~min}$.

Preparation of ATCC cultures was done by: seeding the average pre-enrichment and incubation at $37{ }^{\circ} \mathrm{C}$ for $24 \mathrm{~h}$; counting the colonies in $0.1 \mathrm{~mL}$ culture by selective culture medium separation; and seeding of $0.1 \mathrm{~mL}$ bacterial culture ATCC using sterile swab samples surface.

Identifying target germs: The following standardized methods of bacteriology procedures were used, according to standards in force: SR ISO 16649Escherichia coli; horizontal method for $\beta$-glucuronidase-pozitive Escherichia coli cuantification-Part 2: Colonies counting at $44{ }^{\circ} \mathrm{C}$ using 5-bromo-4-chloro3-indolyl beta-D-glucuronide according to "Minerals Modified Glutamate Broth" (Cat. 1365) producing blue or green-blue collonies on agar glucuronide; SR EN ISO 11290_Listeria monocytogenes; SR EN ISO 6579/2003/AC/2004/AC/2006, Amd.1:2007-Salmonella sp.
Antioxidant activity

\section{(a) DPPH method}

The antioxidant activity test was carried out for PLA nanofibers and PLA/Ag-NP/VitaminE nanofibers. $3 \mathrm{~mL}$ of $10^{-4} \mathrm{M}$ DPPH solution prepared in methanol and in the presence of the nanofibers the decrease in absorbance of DPPH solution at $517 \mathrm{~nm}$ after $30 \mathrm{~min}$ of reaction was measured via UV-VIS NIR Spectroscopy (Varian Cary 5000). The photographs of the solutions were taken after the measurement.

(b) The antioxidant activity of membranes was tested on fresh apple and apple juice by following both sensorial analysis and properties of juice as UV absorbance, $\mathrm{pH}$ and conductivity. A drop of apple juice was dropped on the PLA, PLA/Ag, and PLA/Ag/ Vit E nanofiber membranes. At certain intervals (after $1,2,3,4,24,48$, and $72 \mathrm{~h}$ ), $50 \mu \mathrm{L}$ were extracted from the juice drop, and the $\mathrm{pH}$, conductivity, and absorbance at $450 \mathrm{~nm}$ were recorded. As reference (blank) sample was used a juice drop placed on PET (polyethylene terephthalate) substrate. The $\mathrm{pH}$ and conductivity were measured using WTW InoLab $\mathrm{pH} / \mathrm{ION} /$ Cond 750 multiparameter meter, and the absorbances were measured with a SPECORD 205-222A652 spectrophotometer.

\section{Results and discussion}

Preparation of silver nanoparticles (Ag-NPs) was done by reduction with $\mathrm{N}, \mathrm{N}$-dimethylformamide (DMF) which can act as a powerful reductant for silver salts (Pastoriza-Santos and Liz-Marzan 1999) and was explained in detail under materials and methods section. The reduction process proceeds at a meaningful rate even when performed at room temperature, in the dark and can be observed as a time changing yellow color of the solution due to the plasmon resonance absorption. Visual observation shows that, as the reaction takes place, the color shifts from light yellow to dark brown due to the plasmon resonance absorption (Pastoriza-Santos and Liz-Marzán 2000).

Morphology analysis of nanofibers

Scanning electron microscope (SEM) images and diameter distributions of polylactic acid (PLA) nanofibers and PLA/Ag-NP/VitaminE nanofibers are shown 

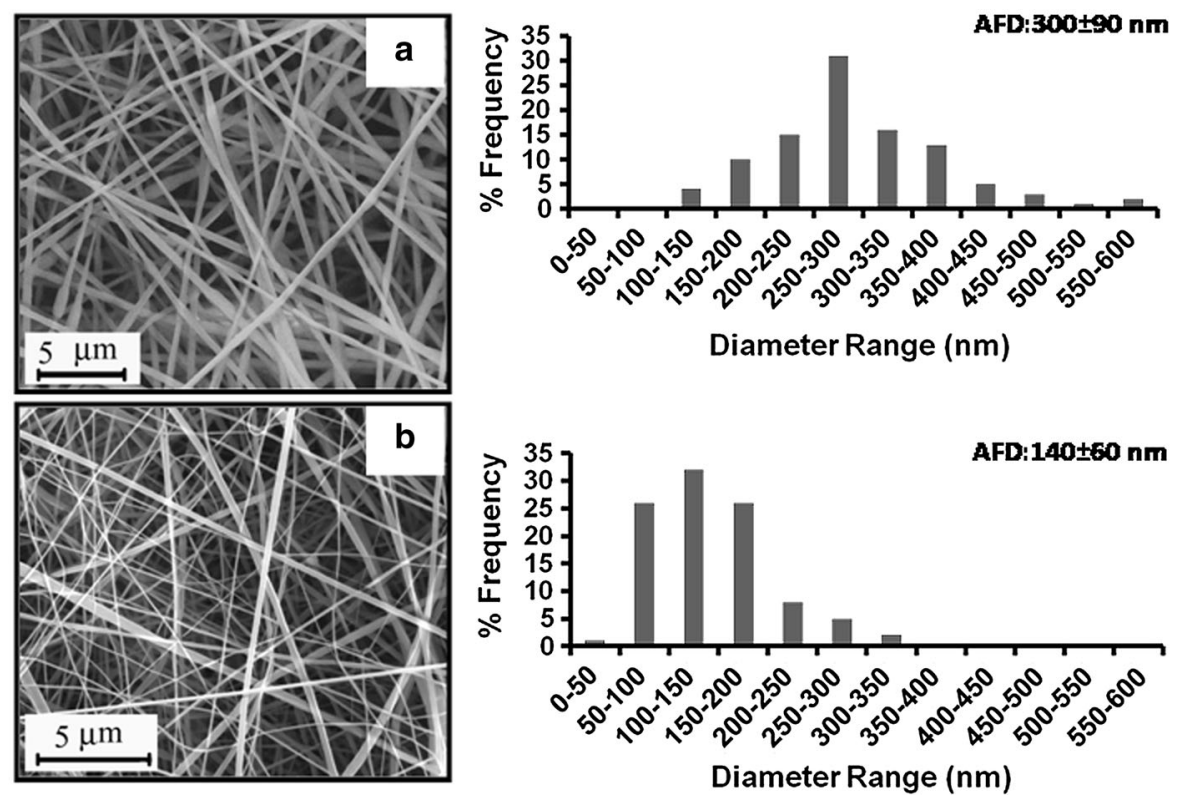

Fig. 1 Representative SEM images and fiber diameter distributions with average fiber diameter (AFD) of the electrospun a PLA and b PLA/Ag-NP/VitaminE nanofibers

in Fig. 1. The average fiber diameter (AFD) was smaller, and diameter distribution was narrower for PLA/Ag-NP/VitaminE nanofibers $(140 \pm 60 \mathrm{~nm})$ (Fig. 1b) in comparison with AFD of PLA nanofibers $(300 \pm 90 \mathrm{~nm})$ (Fig. 1a). The thinner diameter of PLA/Ag-NP/VitaminE nanofibers can be explained by the lower solution viscosity and higher solution conductivity of the PLA/Ag-NP/VitaminE solutions than PLA solution (Table 1) (Wendorff et al. 2012; Ramakrishna 2005; Uyar and Besenbacher 2008). The addition of $\mathrm{AgNO}_{3}$ possibly enhances the charge density of the PLA solution. In addition, the presence of Ag-NP and Vitamin E in PLA solution probably disturbed the chain entanglements of the polymer chains and therefore lower the viscosity of the solution. Hence, PLA/Ag-NP/VitaminE solution having lower viscosity and higher conductivity compared to PLA solution (Table 1) yielded much thinner fibers because of the increased stretching of the jet during the electrospinning. This behavior is very common for the electrospinning of polymer solutions where the low viscosity and high conductivity resulted in much thinner fibers (Uyar and Besenbacher 2008). In addition, SEM images showed that the addition of $\mathrm{Ag}$ and Vitamin $\mathrm{E}$ did not deteriorate the fiber morphology of PLA nanofibers.
Table 1 The representative characteristics of solutions used for electrospinning (composition, viscosity, and conductivity) and of the obtained nanofibers (average diameter, morphology, and antioxidant activity)

\begin{tabular}{lll}
\hline & PLA & $\begin{array}{l}\text { PLA/Ag-NP/ } \\
\text { VitaminE }\end{array}$ \\
\hline PLA content $^{\mathrm{a}}(\mathrm{w} / \mathrm{v})$ & 10 & 10 \\
$\mathrm{Ag} \mathrm{content}^{\mathrm{b}}(\mathrm{w} / \mathrm{w})$ & - & 1 \\
Vitamin E $^{\mathrm{c}}$ & - & 5 \\
content $^{\mathrm{b}}(\mathrm{w} / \mathrm{w})$ & 0.408 & 0.182 \\
Viscosity $(\mathrm{Pa} \cdot \mathrm{s})^{\text {Conductivity }(\mu \mathrm{S} / \mathrm{cm})}$ & 8.82 & 65.00 \\
Average fiber & $300 \pm 90$ & $140 \pm 60$ \\
$\quad$ diameter $(\mathrm{nm})$ & & Bead-free \\
Fiber morphology & Bead-free & nanofibers \\
Antioxidant activity $(\%)$ & 4 & 94 \\
\hline
\end{tabular}

a With respect to solvent
b With respect to polymer (PLA)

Transmission electron microscopy (TEM) and scanning transmission electron microscopy (STEM) images of PLA/Ag-NP/VitaminE nanofibers and diameter distribution for the Ag-NP in PLA/Ag-NP/ VitaminE nanofibers are presented in Fig. 2. The TEM 
Fig. 2 Representative TEM images a higher magnification $\mathbf{b}$ lower magnification and $\mathbf{c}$ STEM image of PLA/Ag-NP/ VitaminE nanofibers and d size distribution for the Ag-NP in PLA/Ag-NP/

VitaminE nanofibers

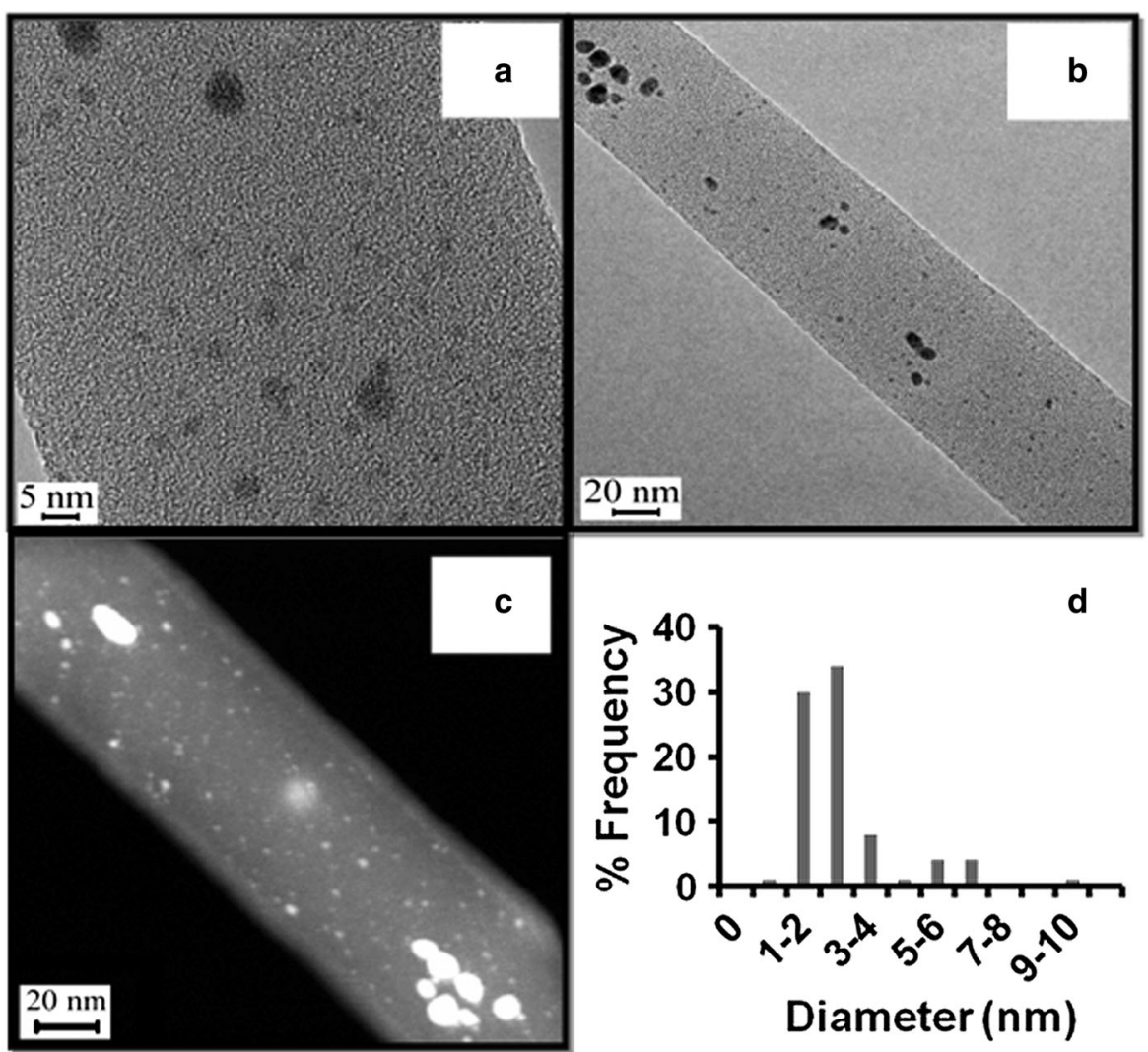

and STEM images of PLA/Ag-NP/VitaminE nanofibers confirmed the presence of Ag-NP in the nanofiber matrix. In addition, Ag-NPs were mostly distributed uniformly within the nanofiber matrix along with few aggregations. The average size of the Ag-NP was determined as $2.7 \pm 1.5 \mathrm{~nm}$ (Fig. 2c). Although the majority of the Ag-NP was around $2 \mathrm{~nm}$, very few bigger Ag-NPs up to $9 \mathrm{~nm}$ were observed in STEM and TEM images (Fig. 2b, c).

\section{Crystalline structure of nanofibers}

X-ray diffraction (XRD) of PLA/Ag-NP/VitaminE nanofibers is given in Fig. 3. The XRD patterns of the PLA/Ag-NP/VitaminE nanofibers show the peak of metallic silver with face-centered cubic (fcc) structure. The peak at $2 \theta=38.1^{\circ}$ corresponds to the three d-spacing (111) (He et al. 2002). The peak at $35.4^{\circ} \mathrm{can}$ be attributed to the strain-induced crystallization of PLA (Chen et al. 2011). Also, the crystalline phase of PLA nanofibers is responsible for appearance of the peaks at $16.7^{\circ}$ (Tábi et al. 2010) and $27.8^{\circ}$ (Srithep

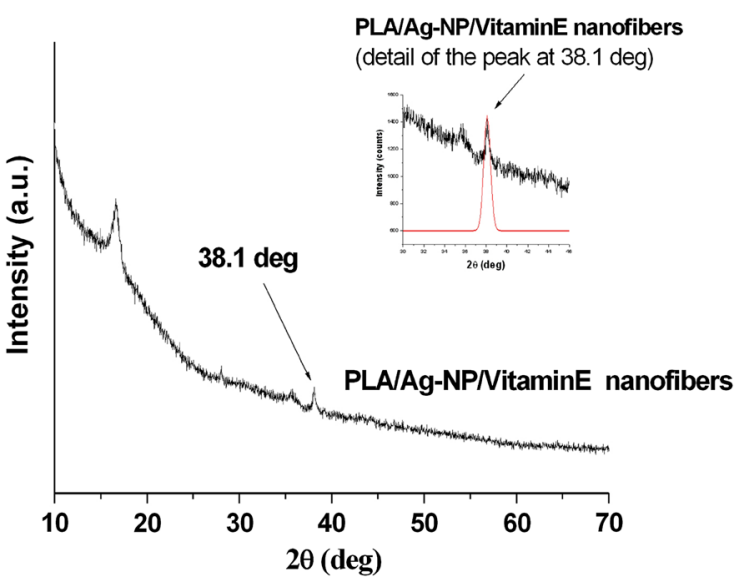

Fig. 3 XRD pattern of PLA/Ag-NP/VitaminE nanofibers with the Lorentz fitted profile

et al. 2013), respectively. The detail of the Lorentz fitted peak at $38.1^{\circ}$ is shown as inset Fig. 3. The broad nature of this XRD peak can be attributed to the small dimensions (nano-size) of the $\mathrm{Ag}$ particles.

Debye-Sherrer formula was used to estimate the average size of the Ag-NP 
$D=\frac{K \cdot \lambda}{B \cdot \cos \theta}$,

where $\lambda$ is the wavelength of the $\mathrm{X}$ rays $(\mathrm{Cu} \lambda$ $K \alpha=1.54 \AA$ ); $K$ is a dimensionless constant that may range from 0.89 to 1.39 depending on the specific geometry of the scattering objects; $B$ is the width of the XRD peak at half maximum; $\theta$ is the diffraction angle; and $D$ is the size of the crystalline domains. For $K=0.9, B=0.043 \mathrm{rad}, 2 \theta=38.09^{\circ}, \lambda=0.154 \mathrm{~nm}$ the formula yields for $D$ approximately $4.0 \mathrm{~nm}$. We can assume that the size of the silver nanoparticles is equal or higher than $4.0 \mathrm{~nm}$, which is well correlated with the value obtained from TEM images.

The release of Ag-NP from nanofibers

The released amount of $\mathrm{Ag}$ ions into aqueous solution was determined by inductively coupled plasma mass spectrometry (ICP-MS). The concentration of released silver ions in deionized water was in $0.13-0.44 \mathrm{ppb}(\mu \mathrm{g} / \mathrm{L})$ range after 10 days of fiber immersion; and the concentration of released silver ions at the end of the experiment ( 20 days) is $0.47 \pm 0.009 \mathrm{ppb}$ (Fig. 4). A prolonged and constant rate release of silver cations can inhibit the growth of bacteria when their concentration is above $0.1 \mu \mathrm{g} / \mathrm{L}$ (ppb) (Joyce-Wöhrmann et al. 2000; Joyce-Wöhrmann and Münstedt 1999; Wuhrmann and Zobrist 1958). It can be assumed that at least a partial antibacterial protection is also assured in surrounding biological fluid. Due to the fact that the most silver remains in fibers after immersion, the antibacterial effect of such fibers will be mainly confined to the bacteria adhering intimately to the PLA fibers (Parolo et al. 2011). Moreover, the European Food Safety Agency (EFSA) stated that in order to attain antibacterial effects, migrated ions ought to be in the range of the legal limit of $50 \mu \mathrm{g} \mathrm{Ag}^{+} / \mathrm{kg}$ food (Fernandez et al. 2010). Thus, our material could be safe for food packaging because its release is lower than legal limit. It can be supposed that the antibacterial activity of such nanofibers will be limited to the media in direct contact with the fibers.

\section{Antibacterial activity of nanofibers}

The results of the antimicrobial testing of the studied nanocomposites against Escherichia coli, Salmonella

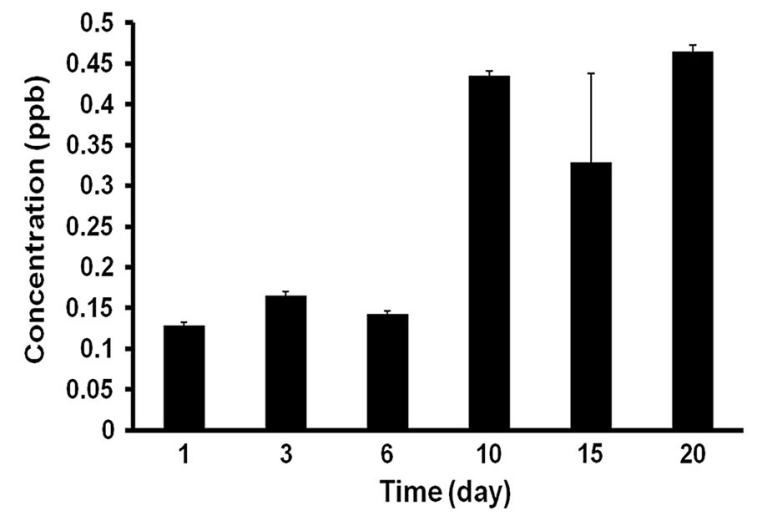

Fig. 4 The amount of silver released in aqueous solution measured by ICP-MS

Table 2 The bacteria growth inactivation in the presence of PLA nanocomposite films, in percent of the control

\begin{tabular}{lcl}
\hline Sample & \% Inhibition 24 h & \% Inhibition 48 h \\
\hline Escherichia coli & & \\
PLA & 34.9 & 52.7 \\
PLA/Ag & 93 & 99 \\
PLA/Ag/VitaminE & 87 & 100 \\
Listeria monocytogenes & \\
PLA & 30.8 & 40.4 \\
PLA/Ag & 100 & 100 \\
PLA/Ag/VitaminE & 100 & 100 \\
Salmonella typhymurium & \\
PLA & 43.87 & 55.48 \\
PLA/Ag & 100 & 100 \\
PLA/Ag/VitaminE & 100 & 100 \\
\hline
\end{tabular}

typhymurium, and Listeria monocytogenes are presented in Table 2 and Fig. 5.

The results indicated that Ag/PLA-NC possessed a strong antibacterial activity against E.coli, Listeria monocytogenes, and Salmonela typhymurium in accordance with literature data (Kamyar et al. 2010). Scientific data report also about antibacterial activity of PLA/Ag system against other bacteria as Staphylococcus aureus (Espinosa-Cristóbal et al. 2009; MohitiAsli et al. 2014) P. aeruginosa, C. albicans, A. niger, and S. cerevisiae (Melaiye et al. 2005). Inhibitory effect of PLA could be explained by acidic $\mathrm{pH}$ imparted by it to the medium ( $\mathrm{pH}-2)$ which is not favorable to bacteria growth and due to the residual content of lactic acid. Some exceptions found at $48 \mathrm{~h}$ of incubation are not only due to the antimicrobial activity but also due to the 


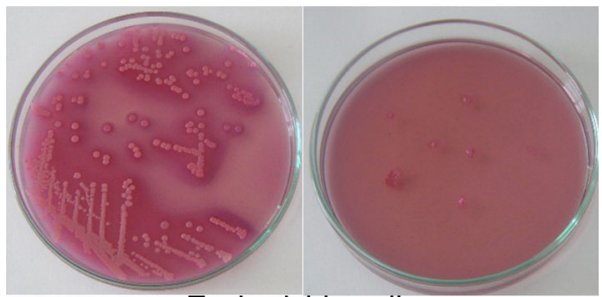

Escherichia coli

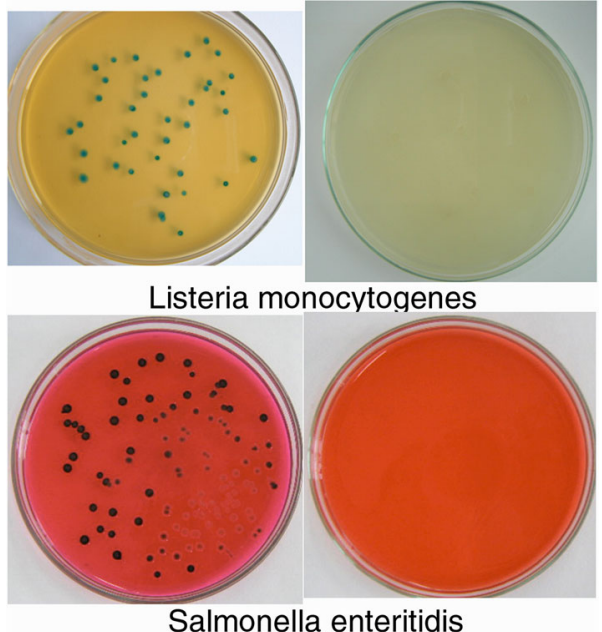

Salmonella enteritidis

Fig. 5 Microscopical aspects of the colonies of Escherichia coli, Listeria monocytogenes, and Salmonella typhymurium grown over PLA/Ag/VitaminE

reduction of the viability of the tested bacteria in the absence of the nutrition medium. Thus, PLA/Ag/ VitaminE nanofibers can be used as an antibacterial scaffold for tissue engineering and medical application as wound dressings for infected wound sites.

Antioxidant activity of nanofibers

\section{DPPH method}

2,2-Diphenyl-1-picrylhydrazyl (DPPH) is a stable radical in solution and appears purple color absorbing at $517 \mathrm{~nm}$ in methanol. The test is based on the principle that DPPH radical on accepting a hydrogen (H) atom from the scavenger molecule i.e., antioxidant, resulting into reduction of DPPH to DPPH2 (Mishra et al. 2012), the purple color changes to yellow with concomitant decrease in absorbance at $517 \mathrm{~nm}$ (Chandrasekar et al. 2006). The free radical scavenging activity of the PLA/Ag-NP/VitaminE nanofibers was measured by UV-VIS spectroscopy recording the decrease in absorbance of DPPH solution at $517 \mathrm{~nm}$ obtained in the absence and presence of the nanofibers. The antioxidant test results and photograph of the solutions after $30 \mathrm{~min}$ of reaction was shown in Fig. 6. Antioxidant activity of PLA nanofibers and PLA/Ag-NP/VitaminE nanofibers are shown in Table 1.

Evaluation of the percentage antioxidant activity was done with formula given below:

$$
\begin{aligned}
\text { Antioxidant activity }= & \left(I_{\mathrm{DPPH}}-I_{\text {nanofiber }}\right) / \\
& I_{\mathrm{DPPH}} * 100,
\end{aligned}
$$

where $I_{\mathrm{DPPH}}$ is absorbance at $517 \mathrm{~nm}$ of pure DPPH and $I_{\text {nanofiber }}$ is absorbance at $517 \mathrm{~nm}$ of DPPH in the presence of nanofibers. The purple color of solution turned into yellow after $30 \mathrm{~min}$ of reaction, which means that there was no more DPPH molecule in PLA/ Ag-NP/VitaminE solution. PLA nanofibers exhibited only $4 \%$ of antioxidant activity, whereas PLA/AgNP/VitaminE nanofibers have $94 \%$ antioxidant activity. Although PLA nanofibers do not contain any antioxidant agent, they also showed $4 \%$ antioxidant activity. The small antioxidant activity of PLA nanofibers could be due to the residual lactic acid of nanofibers (Theinsathid et al. 2011).

\section{Enzymatic browning of apples}

Enzymatic browning of apples (fruits) is a process caused by the oxidation of phenolic compounds into quinones (Queiroz et al. 2008). This reaction is mainly catalyzed by polyphenol oxidase in the presence of oxygen and causes the brown pigmentation together with organoleptic and nutritional modifications in the apple tissues. The polyphenol oxidase activity increases after the fruit peeling or cutting. There are studies showing the antibrowning effect of antioxidants such as cysteine (Arpita et al. 2010), ascorbic acid (Rapeanu et al. 2006), and tropolone (NunezDelicado et al. 2007).

The purpose of the following procedure is to evaluate the antibrowning (inhibition of polyphenol oxidase activity) effect of Vitamin E containing PLA fibers on fresh apple and apple juice.

Generally in the presence of the combination of $\mathrm{Ag}$ and Vitamin E the apple, and its juice kept their general aspects and properties a longer time period, the change in color or browning do not appear after $48 \mathrm{~h}$, while for other samples the changes appear after 


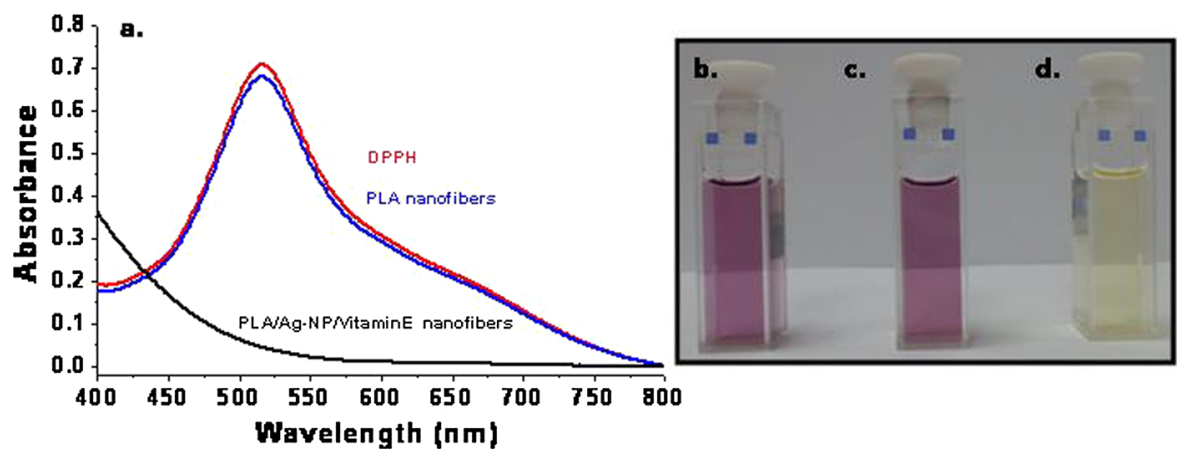

Fig. 6 a UV spectra of DPPH solution; in the presence of PLA nanofibers, and PLA/Ag-NP/VitaminE nanofibers; the aspect of $\mathbf{b}$ the DPPH solution in the absence and $\mathbf{c}$ the presence of PLA nanofibers, and $\mathbf{d}$ PLA/Ag-NP/VitaminE nanofibers

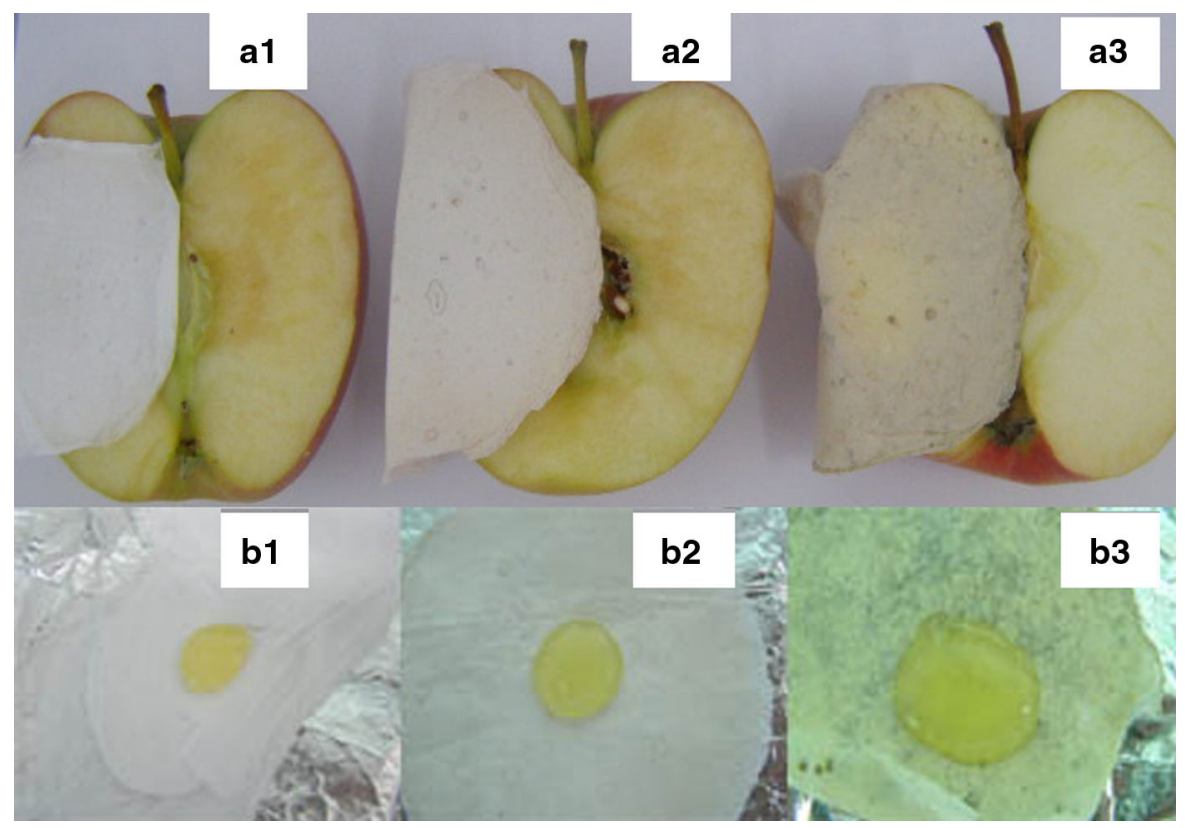

Fig. 7 Aspects of the apples and apple juice in contact with the PLA (a1 and b1), PLA/Ag (a2 and b2), and PLA/Ag/Vitamin E (a3 and b3) membranes after $24 \mathrm{~h}$

$24 \mathrm{~h}$ or less ( $2 \mathrm{~h}$ for juice placed on PET as commercial packaging material—see Fig. 7, 8).

The inhibition of polyphenol oxidase activity was assayed by measuring the rate of increase in absorbance at $450 \mathrm{~nm}$ (Jeong et al. 2008; Arpita et al. 2010). Higher values for absorbance at $450 \mathrm{~nm}$ correspond to higher browning/darkening of the juice. The absorbance (Fig. 8a), conductivity (Fig. 8b), and $\mathrm{pH}$ (Fig. 8c) insignificantly vary for apple juice placed on PLA/Ag/Vitamin E nanofiber membrane in comparison with PLA and PLA/Ag demonstrating the antioxidant/antibrowning effect of Vitamin $\mathrm{E}$ incorporation in PLA. The results indicated that the PLA/Ag/Vitamin E nanofiber membranes actively reduced the polyphenol oxidase activity.

Recently, in a situation similar with the studied system (Ramos et al. 2014a; Ramos et al. 2014b) has been demonstrated that the presence of Ag-NP and thymol antioxidant in PLA matrix also improved its degradability. Degradation of these PLA-based nanocomposites with thymol and silver nanoparticles in composting conditions indicated that the inherent biodegradable character of this biopolymer was improved after such modification. The obtained 

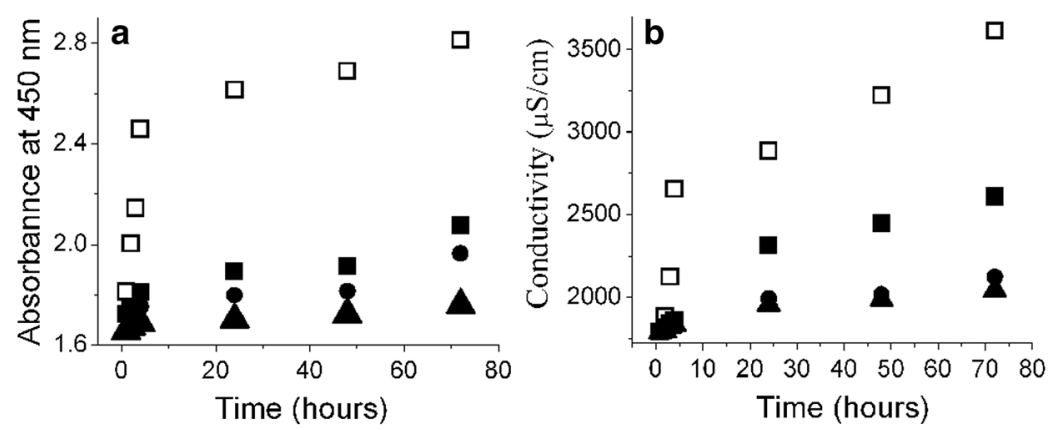

Fig. 8 Variation in time of the absorbance at $450 \mathrm{~nm}(\mathbf{a}), \mathrm{pH}$ (b) and conductivity of the apple juice in presence of PLA nanofiber membranes in comparison with juice on PET (apple

nanocomposites showed suitable properties to be used as biodegradable active-food packaging systems with antioxidant and antimicrobial effects. Moreover, biodegradable nanocomposites prepared have good potential for food packaging application accomplishing also environmental concerns.

\section{Conclusion}

Multifunctional PLA nanofibers containing Ag-NP and VitaminE have been obtained via electrospinning. The characterization of PLA/Ag-NP/VitaminE nanofibers was performed by SEM, TEM and XRD. Ag-NP has average diameter of $2.7 \pm 1.5 \mathrm{~nm}$ within the PLA nanofiber matrix with a few aggregates. By incorporating two active agents (Ag-NP and Vitamin $\mathrm{E}$ ) in the electrospun PLA nanofibers, PLA/Ag-NP/VitaminE nanofibers have shown both antibacterial activity and antioxidant activity. PLA/Ag-NP/VitaminE nanofibers inhibited growth of Escherichia coli, Listeria monocytogenes, and Salmonella typhymurium up to $100 \%$ whereas the antioxidant activity of PLA/AgNP/VitaminE nanofibers was determined as $94 \%$. The results of the tests on fresh apple and apple juice indicated that the PLA/Ag/VitaminE nanofiber membrane actively reduced the polyphenol oxidase activity. The amount of silver released into aqueous solution was measured via ICP-MS and remained constant after 10 days of immersion and this suggested that antibacterial activity of PLA/Ag-NP/VitaminE nanofibers can last for a longer time period. These materials could find application in food industry as a potential preservative packaging for fruits and juices. juice on: unfilled rectangle PET, filled rectangle PLA, filled circle PLA/Ag, and filled triangle PLA/Ag/Vitamin E)

Acknowledgments The authors acknowledge financial support by COST FA0904 Action for he STSM-110313026173 "New potential applications in food packaging of the electrospinning/electrospraying method used for polymer surface modification and to obtain of nano (micro) structures from antimicrobial agents as chitosan, silver and various bioactive agents" and by UEFISCDI for 164/2012 project and to IAEA for RC-17689 R0/2013. State Planning Organization (DPT) of Turkey is acknowledged for the support of UNAMInstitute of Materials Science and Nanotechnology. Dr. Uyar acknowledges The Scientific and Technological Research Council of Turkey (TUBITAK) (Project \# 111M459) and EU FP7-PEOPLE-2009-RG Marie Curie-IRG (NANOWEB, PIRG06-GA-2009-256428) and The Turkish Academy of Sciences-Outstanding Young Scientists Award Program (TUBA-GEBIP) for funding the research. Z. Aytac thanks to TUBITAK (Project \#111M459) for the PhD scholarship.

\section{References}

Arpita S, Subroto D, Pinaki B, Bidyut B (2010) Inhibition of polyphenol oxidase in banana, apple and mushroom by using different antibrowning agents under different conditions. Int J Chem Sci 8:S550-S558

Chandrasekar D, Madhusudhana K, Ramakrishna S, Prakash Diwan V (2006) Determination of DPPH free radical scavenging activity by reversed-phase HPLC: a sensitive screening method for polyherbal formulations. J Pharm Biomed Anal 40:460-464

Chen X, Kalish J, Ling Hsu S (2011) Structure Evolution of alpha'-Phase Poly(lactic acid). J Polym Sci, Part B: Polym Phys 49:1446-1454

Choi Y, Nirmala R, Lee JY, Rahman M, Hong S-T, Kim HY (2013) Antibacterial ciprofloxacin $\mathrm{HCl}$ incorporated polyurethane composite nanofibers via electrospinning for biomedical applications. Ceram Int 39:4937-4944

Doshi J, Reneker DH (2007) Electrospinning process and applications of electrospun fibers. J Electrost 35:151-160

Dumitriu RP, Munteanu BS, Pâslaru E, Vasile C (2014) Electrospraying of Chitosan/Vitamin E mixtures for bioactive coatings. International congress on green chemistry and 
sustainable engineering, Barcelona, 29-31 July 2014 Book of abstract p. 117

Espinosa-Cristóbal LF, Martínez-Castañón GA, MartínezMartínez RE, Loyola-Rodríguez JP, Patiño-Marín N, Reyes-Macías JF, Ruiz F (2009) Antibacterial effect of silver nanoparticles against Streptococcus mutans. Mater Lett 63:2603-2606

Fernandez A, Torres-Giner S, Lagaron JM (2009) Novel route to stabilization of bioactive antioxidants by encapsulation in electrospun fibers of zein prolamine. Food Hydrocoll 23:1427-1432

Fernandez A, Soriano E, Hernandez-Munoz P, Gavara R (2010) Migration of antimicrobial silver from composites of polylactide with silver zeolites. J Food Sci 75:E186-E193

Gangadharan D, Harshvardan K, Gnanasekar G, Dixit D, Popat KM, Anand PS (2010) Polymeric microspheres containing silver nanoparticles as a bactericidal agent for water disinfection. Water Res 44:5481-5487

Gu S-Y, Wang Z-M, Ren J, Zhang C-Y (2009) Electrospinning of gelatin and gelatin/poly(L-lactide) blend and its characteristics for wound dressing. Mater Sci Eng: C 29:1822-1828

He R, Qian X, Yin J, Zhu Z (2002) Preparation of polychrome silver nanoparticles in different solvents. J Mater Chem 12:3783-3786

Jeong HL, Jin WJ, Kwang DM, Kee JP (2008) Effects of antibrowning agents on polyphenol oxidase activity and total phenolics as related to browning of fresh-cut 'fuji' apple. ASEAN Food J 15:79-87

Joyce-Wöhrmann RM, Münstedt H (1999) Determination of the silver ion release from polyurethanes enriched with silver. Infection 27(Supplement-1):S46-S48

Joyce-Wöhrmann RM, Hentschel T, Münstedt H (2000) Thermoplastic silver-filled polyurethanes for antimicrobial catheters. Adv Eng Mater 2:380-386

Kamyar S, Mansor BA, Wan MZWY, Nor AI, Russly AR, Maryam J, Majid D (2010) Silver/poly (lactic acid) nanocomposites: preparation, characterization, and antibacterial activity. Int J Nanomedicine 5:573-579

Kayaci F, Uyar T (2012) Encapsulation of vanillin/cyclodextrin inclusion complex in electrospun polyvinyl alcohol (PVA) nanowebs: prolonged shelf-life and high temperature stability of vanillin. Food Chem 133:641-649

Kayaci F, Ertas Y, Uyar T (2013a) Enhanced thermal stability of eugenol by cyclodextrin inclusion complex encapsulated in electrospun polymeric nanofibers. J Agric Food Chem 61:8156-8165. doi:10.1021/jf402923c

Kayaci F, Umu Oco, Tekinay T, Uyar T (2013b) Antibacterial electrospun polylactic acid (PLA) nanofibrous webs incorporating triclosan/cyclodextrin inclusion complexes. J Agric Food Chem 61:3901-3908

Lee SJ, Lee SG, Kim H, Kim JR, Young C, Kim SG, Lyoo WS (2007) Preparation of hydrophilic antioxidant-loaded poly(Vinyl Alcohol) Nanoweb by electrospinning and its wound healing effect. In: Gdoutos EE (ed) Experimental analysis of nano and engineering materials and structures, Proceedings of the 13th international conference on experimental mechanics, Alexandroupolis, Greece, July 1-6 2007 Springer, pp 49-50

Melaiye A, Sun Z, Hindi K, Milsted A, Ely D, Reneker DH, Tessier CA, Youngs WJ (2005) Silver(I)—imidazole cyclophane gem-diol complexes encapsulated by electrospun tecophilic nanofibers: formation of nanosilver particles and antimicrobial activity. J Am Chem Soc 127:2285-2291

Merrell JG, McLaughlin SW, Tie L, Laurencin CT, Chen AF, Nair LS (2009) Curcumin loaded poly(e-Caprolactone) nanofibers: diabetic wound dressing with antioxidant and anti-inflammatory properties. Clin Exper Pharmacol Physiol 36:1149-1156

Mishra K, Ojha H, Chaudhury NK (2012) Estimation of antiradical properties of antioxidants using DPPH assay: a critical review and results. Food Chem 130:1036-1043

Mohiti-Asli M, Pourdeyhimi B, Loboa EG (2014) Skin tissue engineering for the infected wound site: biodegradable pla nanofibers and a novel approach for silver ion release evaluated in a $3 \mathrm{D}$ coculture system of keratinocytes and Staphylococcus aureus. Tissue Eng Part C Methods Mar 21. doi: $10.1089 /$ ten.tec. 2013.0458

Morones JR, Elechiguerra JL, Camacho A, Holt K, Kouri JB, Ramírez JT, Yacaman MJ (2005) The bactericidal effect of silver nanoparticles. Nanotechnology 16:2346-2353

Nunez-Delicado E, Serrano-Megias M, Perez-Lopez AJ, LopezNicolas JM (2007) Characterization of polyphenol oxidase from Napoleon grape. Food Chem 100:108-114

Panácek A, Kvítek L, Prucek R, Kolár M, Vecerová R, Pizúrová N, Sharma VK, Nevecná T, Zboril R (2006) Silver colloid nanoparticles: synthesis, characterization, and their antibacterial activity. J Phys Chem B 110:16248-16253

Pant B, Pant HR, Pandeya DR, Panthi G, Nam KT, Hong ST, Kim CS, Kim HY (2012) Characterization and antibacterial properties of Ag NPs loaded nylon-6 nanocomposite prepared by one-step electrospinning process. Colloids Surfaces A: Physicochem Eng Aspects 395:94-99

Parolo ME, Fernández LG, Zajonkovsky I, Sánchez MP, Baschini M (2011) Antibacterial activity of materials synthesized from clay minerals, Science against microbial pathogens: communicating current research and technological advances.In: Méndez-Vilas A (Ed) FORMATEX 2011, p. 144-151. http://www.formatex.info/microbiology3/ book/144-151.pdf

Pastoriza-Santos I, Liz-Marzan LM (1999) Formation and stabilization of silver nanoparticles through reduction by $\mathrm{N}$, N-Dimethylformamide. Langmuir 15:948-951

Pastoriza-Santos I, Liz-Marzán LM (2000) Reduction of silver nanoparticles in DMF. Formation of monolayers and stable colloids. Pure Appl Chem 72:83-90

Queiroz C, Lopes MLM, Fialho E, Valente-Mesquita VL (2008) Polyphenol oxidase: characteristics and mechanisms of browning control. Food Rev Int 24:361-375

Ramakrishna S (2005) An introduction to electrospinning and nanofibers. World Scientific Publishing Company Incorporated, Singapore

Ramos M, Fortunati E, Peltzer M, Dominici F, Jiménez A, del Carmen Garrigós M, Kenny JM (2014a) Influence of thymol and silver nanoparticles on the degradation of poly(lactic acid) based nanocomposites: thermal and morphological properties. Polym Degrad Stab. doi:10. 1016/j.polymdegradstab.2014.02.011

Ramos M, Jiménez A, Peltzer M, Garrigó MC (2014b) Development of novel nano-biocomposite antioxidant films 
based on poly (lactic acid) and thymol for active packaging. Food Chem 162:14-155

Rapeanu G, Van Loey A, Smout C, Hendrickx M (2006) Biochemical characterization and process stability of polyphenol oxidase extracted from Victoria grape (Vitis vinifera ssp. Sativa). Food Chem 94:253-261

Shi Q, Vitchuli N, Nowak J, Caldwell JM, Breidt F, Bourham M, Zhang X, McCord M (2011) Durable antibacterial Ag/ polyacrylonitrile (Ag/PAN) hybrid nanofibers prepared by atmospheric plasma treatment and electrospinning. Eur Polym J 47:1402-1409

Srithep Y, Nealey P, Turng LS (2013) Effects of annealing time and temperature on the crystallinity and heat resistance behavior of injection-molded poly(lactic acid). Polym Eng Sci 53:580-588

Suwantong O, Ruktanonchai U, Supaphol P (2010) In vitro biological evaluation of electrospun cellulose acetate fiber mats containing asiaticoside or curcumin. J Biomed Mater Res Part A 94A:1216-1225

Tábi T, Sajó IE, Szabó F, Luyt AS, Kovács JG (2010) Crystalline structure of annealed polylactic acid and its relation to processing. Express Polym Lett 4:659-668

Theinsathid P, Visessanguan W, Kingcha Y, Keeratipibul S (2011) Antimicrobial effectiveness of biobased film against Escherichia coli 0157:h7, Listeria monocytogenes and Salmonella typhimurium. Adv J Food Sci Technol 3:294-302
Tijing LD, Ruelo MTG, Amarjargal A, Pant HR, Park C-H, Kim CS (2012) One-step fabrication of antibacterial [silver nanoparticles/poly(ethylene oxide)]—polyurethane bicomponent hybrid nanofibrous mat by dual-spinneret electrospinning. Mater Chem Phys 134:557-561

Traber MG, Atkinson J (2007) Vitamin E, antioxidant and nothing more. Free Radic Biol Med 43:4-15

Uyar T, Besenbacher F (2008) Electrospinning of uniform polystyrene fibers: the effect of solvent conductivity. Polymer 49:5336-5343

Vasile C, Lungu M, Macocinschi D, Pâslaru E, Dumitriu RP, Coroiu V, Constantin D (2013) Polyurethane/Natural compounds-based composite materials containing silver nanoparticles. NanotechItaly, Venice, Italy, 27-29 Nov 2013 Book of abstracts p 99

Wendorff JH, Agarwal S, Greiner A (2012) Electrospinning: materials, processing, and applications. John Wiley \& Sons, Germany

Wuhrmann K, Zobrist F (1958) Untersuchungen über die bakterizide wirkung von silber in Wasser. Schweizerische Zeit Hydrologie 20:218-254

Xu X, Yang Q, Wang Y, Yu H, Chen X, Jing X (2006) Biodegradable electrospun poly(L-lactide) fibers containing antibacterial silver nanoparticles. Eur Polym J 42:2081-2087

Zhou Y, Lim LT (2009) Activation of lactoperoxidase system in milk by glucose oxidase immobilized in electrospun polylactide microfibers. J Food Sci 74:C170-C176 